\title{
The Study of Mathematics - an Investment with Profound Implications for the Future of the Romanian Society
}

\author{
Brânduşa Prepeliţă Răileanu \\ University Politehnica" of Bucharest \\ Faculty of Engineering in Foreign Languages \\ Splaiul Independenţei 313, Ro-060032 \\ Bucharest, Romania
}

\author{
Oana Păstae \\ Constantin Brancusi University, \\ College of Letters and Social Sciences, \\ 1, Grivitei Street, Targu Jiu, \\ Gorj, Romania
}

\begin{abstract}
The paper highlights the fact that in Romania, the Reform of Education, Training and Human Resource Development is an integral part of the transition to a democratic society and market economy. Having as starting point the research performed within the project developed under the patronage of the Romanian Ministry of Education, POSDRU/56/1.2/S/32768, project entitled The Training of University Teachers and Students in the Field of Using Modern Tools to Teach-Learn-Assess for the Mathematical Subjects in Order to Acquire Important Professional and Practical Skills for the Labour Market, the paper emphasizes the fact that Romania has made progress in all these areas since the Reform of Education began. The paper proves that harmonizing the curriculum for the mathematical disciplines taught in technical higher education is a challenge to promote and support changes that meet the needs of the new economy and society as well as the interests of all young people and adults, in the face of a shortage of financial and human resources. The rapid expansion of higher education and its growing cost are focusing attention on issues of quality, relevance and efficiency for mathematical subjects.
\end{abstract}

Keywords - curriculum, mathematical skills, technical education, teaching, learning, assessment, training programs, syllabus, quality, higher education.

\section{A STRATEGIC THINKING AND CONTROL}

The determination of quality in education is a dynamic approach which means implication and responsibility, on the one hand, as well as strategic thinking and control, on the other hand. In order to determine quality in higher education, the presence of professors with experience and thorough training is necessary. The professors should want to be involved in the teaching - learning process, being good organizers, close to the changes of the environment in which they conduct their activity.

The role of the professor in the process of teachinglearning is essential. In order to be efficient, professors should have considerable talent and pedagogical skills, as well as human characteristic features. The improvement of quality and professors' motivation should become priorities of all the states in the world. Some of the domains in which progress could be achieved are: selection, initial education, training at the job, through the development of the postgraduate programs. In order to facilitate the professors' access to such programs, they should benefit from proper communication skills.

A good program to determine the quality of the educational methods should:

- State the purpose and the kind of educational measures.

According to the context, the government initiates and supports the dialogue with the universities and it aims at an agreement regarding clear educational purposes and a proper curriculum. Within these issues, the key questions are: ,What does really mean quality?' and 'How can quality be measured or represented?

- Assign the responsibility of determining the quality in education to the main actors - universities and professors. It should ensure that these key-actors are helped in order to obtain information regarding quality and the impact of their activity and to find the proper answers /solutions.

- Help to assume the sense of responsibility towards the daily activity of the university as well as towards the commitment to reach higher standards.

The major preoccupations for the quality of the educational act were mainly due to the role and responsibilities of universities within a Europe of Knowledge" which were emphasized at various international meetings on this subject: - by the much higher level of education based on intensive knowledge of a continuously growing number of students, the universities contribute to the strengthening of the competitiveness of European economy;

- by the knowledge transmitted to the specialists being trained, the universities have an overwhelming contribution to the 
raising of the extent of occupation of the work force and to the achievement of social cohesion;

- by the values and ethical norms which lie at the basis of their functioning, the universities have a great influence not only on the academic life of the students and of the university staff but also on the moral aspect of the whole society.

Besides all mentioned above, the increase of the interest in the quality of the educational act is also due to the following tendencies and characteristics:

- the mass character of university studies, by the increase of the demand of training in this field;

- the continuous transformation of the role held by the institutions in the field of education and research;

- the increase of the number of programs of long-distance education (national and international);

- the ever more ample need of information and research;

- the tendency of development, at a national and regional level, of an ever closer cooperation between universities and the business environment;

- the tendency of the business environment of sub-contracting its own research activities to the universities with the best results;

- the need of mobility of the students by the exponential growth rate of the international student exchanges;

- the transnational development of university studies by franchise, campus brands and other similar arrangements;

- the mutual recognition of university degrees among the various states of the world.

In Romania, the legislative framework of assuring the quality of the educational services in the institutes of higher education is ensured by the Law no 87/10.04.2006. In the light of this normative act, the assurance of the quality of education refers to a number of criteria and to the following domains: institutional capacity, educational efficiency and the management of quality. Among the main objectives of quality assurance, we can mention the supply of information connected to the functioning of the educational system, to the recorded results and to the possible ways of improving these results; the assuming of responsibility for the creation of conditions favorable to attaining quality; the maintenance and improvement of high academic standards; the demonstration of a high quality of the curricula for academic or professional training, initial and continuous for all the students and learners in an institute of higher education; the development of an institutional culture of quality and the ensuring of a real protection of the education beneficiary - student/learner.

\section{SKILLS AND ATTITUDES}

The objectives mentioned above have a high degree of generality and complexity. They are linked to the acquiring of certain skills and attitudes that are specific to the respective subject, objectives that are pursued along several years of study.

In order to achieve the established objectives, several types of learning activities can be organized. The syllabus offers at least one example of such activities for each objective. The examples of learning activities are conceived so that they start from the concrete experience of the students to be included into didactic strategies appropriate for the various learning contexts.

Discussions which took place within the program developed under the patronage of the Romanian Ministry of Education, POSDRU/56/1.2/S/32768, project entitled The Training of University Teachers and Students in the Field of Using Modern Tools to Teach-Learn-Assess for the Mathematical Subjects in Order to Acquire Important Professional and Practical Skills for the Labour Market have focused on the quality of science and mathematics education and training. Funded by the European Social Fund, the project aimed to adapt the study programs of mathematical disciplines to the labour market demands and the creation of mechanisms and tools to extend learning opportunities.

The project covered a period of 36 months contributing directly to the general objective of Sector Operational Program of Human Resources Development - POSDRU and entered in the field of intervention 1.2 Quality in higher education. The project was implemented by the Ministry of Education, Research and Innovation in collaboration with The Red Point, Agency OSC, University Politehnica of Bucharest, University of Bucharest, University of Civil Engineering of Bucharest, University of Pitesti, Technical University Gheorghe Asachi of Iassy, West University of Timisoara, University of Galati, Technical University of Cluj-Napoca and University of Alba-Iulia.

Each of the universities participating in this project have created one training centre for teachers and students involved in increasing the quality of Mathematical education in Romania and in developing best practice on national and international level.

The specific objectives of the project were:

- Assessment of educational needs, of teachers' and students' aims related to the use of mathematics in higher education, masters and doctorates;

- Analysis of the effectiveness and relevance of current curricula at the level of performance and efficiency, to develop knowledge and skills for students who study mathematical subjects at university;

- Development and harmonization of university curricula of mathematical disciplines, according to the demands of the labour market;

- Development and implementation of a training program for teachers and students interested in partner universities based on the development and harmonization of curricula;

- Creation of 9 training centers for teachers and students involved in increasing the quality of mathematical education in Romania and in developing the best practice on national and international level;

- Creation of a resource base of innovative, modern and functional teach-learn-assess for the mathematical subjects in universities; 
- Development of a portal online as a source of teaching resources for teachers and students who wish to improve their knowledge in the field of Mathematics, as well as a modern and flexible instrument of communication, learning and assessment;

- Fostering of cooperation and communication between students;

- Use of new knowledge and skills in the labor market.

An important aspect of Romanian efforts to improve economic competitiveness is the existence of a capable scientific and technological workforce. Concern has been expressed about the future ability of the science and engineering base to generate the technological advances needed to maintain economic growth [8]. Some discussions have focused on the quality of science and mathematics for students' education and training. The design and structure of the scientific curriculum are thought to discourage a number of highly qualified students from entering and remaining in the disciplines. Other discussions have focused on the scientific knowledge of those students entering other disciplines. Even students pursuing nonscientific and nonmathematical major subjects will require basic knowledge of scientific and technological applications and mathematical reasoning in order to adapt to constant changes in the labour market.

A national strategy that is intended to emphasize that graduate programs should provide a wider variety of career options for their students. This could be accomplished in a program that has a student grounded in the fundamentals of one field that is enhanced by a breadth of knowledge in a related field [6]. Added to such a program would be offcampus experiences exposing the student to the skills requested by an increasing number of employers: the ability to communicate complex ideas, and the experiences of working in groups of interdependent workers.

\section{NEW EDUCATIONAL TECHNIQUES}

The new reforms initiated by the Romanian Ministry of Education prove that the importance of the technical higher education has been increasing year by year. This increase is an important factor in the development of new educational techniques. To begin with, we specify that in the domain of the technical higher education the main aims are the creation of the institutional autonomy of universities from a financial, didactic and human resources point of view and especially the promotion of this autonomy as regards the defining of local curriculum. We can also mention the complete selfmanagement of extra-budgetary resources by the educational units; the drawing up of programs for the managerial training as part of the basic training of the teaching staff; the promoting of the contractual relation in partnerships between the education units and their social partners that are interested in the educational domain; the promoting of postgraduate training and the reorganization of its financing.

A concrete example is the master program ITEMS (Techniques for Analysis, Modelling and Simulation for Imaging, Bioinformatics and Complex Systems) which has been conceived as a research master at the confluence of information technology (hard/soft) with domains with an exponential development: imaging, bioinformatics, and complex systems the progress of which has had a tremendous impact scientifically, technologically and socially. The financing is provided through the contract POS DRU/86/1.2/S/61756 (European post-accession funds).

The master program ITEMS has four terms (the last being entirely dedicated to elaborating the master thesis either in a laboratory of one of the partners - University POLITEHNICA of Bucharest, University of Oradea, University Transilvania of Braşov or in a laboratory abroad in U.E. or U.S.A.) and a four weeks summer school.

This master program aims to provide a solid and modern theoretical and practical basis - at the level of renowned foreign masters - to future design engineers and/or scientists. Most graduates will continue their training with the doctoral program. From this fundamental objective the secondary objectives on course selection have derived; in particular, in the first term, the training in mathematics and physics is resumed in a modern version similar to that used in famous universities abroad.

A second objective of the project is to develop a program attractive to students from all over Europe - that is, the evolution of the master towards a European Master - and the creation of a European center of excellence in the directions of modelling and simulation, and data analysis systems.

In accordance with the fundamental objective, graduates of the masters program will have the necessary skills of a design engineer and of a young researcher: the ability to identify and analyse problems of modelling, simulation, design, transmission, storage, etc. in various practical applications in these areas.

Among the didactic methods mentioned in the syllabuses the most important ones might be those leading to a new type of communication between the teacher and the student and among students during classes, thus developing the team spirit and cooperation among the members of the group. The method of the project and the requirement of making individual folders - the use of which has been generalized lately in the didactic documents and strategies and which are gradually becoming a common practice in class - are introducing a new kind of individual and/or group activity of the students, emphasizing the development of the originality, creativity and independence of the students in carrying out certain coherent learning tasks.

In order to answer the challenges of the future, the Romanian teacher will have to become a facilitator of the learning process, encouraging individual development and increasing the opportunities of the student for group and selfstudy. Besides the planning activities, he will have to organize the group involved in the learning and researching process and become flexible enough to be able to face unforeseen and even temporary situations of conflict. The teacher will have the opportunity to go beyond the narrow, protected framework of the classroom and start to work together with his/her colleagues. 
It should not be taken for granted that engineering students understand the need to study mathematics in the first place. When, after the first few lectures of the course, the professor asks the students to complete feedback forms, and about $55 \%$ of the students complained that the course was too academic, something in teaching is wrong. This general mood is coming from the idea: we are mostly not academics but practical engineers; we forget what we are told but never forget what we see or discover for ourselves! It is clear that the professor made at least two mistakes in designing the course. Firstly, the theory was indeed not properly balanced with practical applications. Secondly, the need for the theoretical part was not well explained at the beginning of the course. The professor had to put things right in order to complete the course successfully. There are obvious natural limits to the depth of the mathematical analysis. If we don't set these limits we can, in theory, end up studying topology (the foundations of mathematics) ad infinitum. Our brain may be working very hard, but its direct contribution to the science of engineering would be negligible. On the other hand, there are not so many objects that can be physically touched in modern engineering. For example, one cannot touch the boundary layer of a supersonic aircraft or the inside of a working internal combustion engine. In order to study them one needs to describe them as abstract concepts in terms of mathematical equations.

In Romania, the Reform of Education, Training and Human Resource Development is an integral part of the transition to a democratic society and market economy. Harmonizing the curriculum for the mathematical disciplines taught in higher technical education is a challenge to promote and support changes that meet the needs of the new economy and society as well as the interests of all young people and adults, in the face of a shortage of financial and human resources. The rapid expansion of higher education and its growing cost are focusing attention on issues of quality, relevance and efficiency for mathematical subjects.

The Romanian project to which I referred previously is financed from the European Social Fund through the Sectorial Operational Program for the Development of Human Resources 2007 - 2013 and is entitled The Training of University Teachers and Students in the Field of Using Modern Tools to Teach-Learn-Assess for the Mathematical Subjects in Order to Acquire Important Professional and Practical Skills for the Labour Market.

The problems of the curriculum represent one of the main issues of this project developed under the patronage of the Ministry of Education having as main domain of intervention The Quality in Higher Education.

A curriculum is an essential step in the process of ongoing curriculum development and implementation [2]. Such a curriculum must earn acceptance by teachers and must be deemed educationally valid by the academic community at large. This acceptance will be far easier to attain when the curriculum guide is:

A curriculum for the subjects in mathematics is a structured document that delineates the goals, objectives, learning experiences, instructional resources and assessments that comprise a specific educational program. Additionally, it represents an articulation of what students should know and be able to do and supports teachers in knowing how to achieve these goals.

Accordingly, an exemplary curriculum is a tool that assists in planning and implementing a high quality instructional program. It:

- establishes a clear set of overarching goals that guide the entire program and the decisions that affect each aspect of the program;

- $\quad$ establishes sequences both within and between levels and assures a coherent and articulated progression from grade to grade;

- outlines a basic framework for what to do, how to do it, when to do it and how to know if it has been achieved;

- allows for flexibility and encourages experimentation and innovation within an overall structure;

- promotes interdisciplinary approaches and the integration of curriculum when appropriate;

- $\quad$ suggests methods of assessing the achievement of the program's goals and objectives;

- $\quad$ provides a means for its own ongoing revision and improvement; and

- provides direction for procurement of human, material and fiscal resources to implement the program.

Formal lectures alone are not particularly effective in teaching mathematics because of a number of reasons. Mathematical courses are built in such a way that if a student misses a key concept at the beginning of the lecture, the rest of the lecture can be lost for him/her. Besides, every student has his/her own pace of acquiring mathematical knowledge. The pace of the lecture can be too slow for some students and too quick for others. Finally, formal lectures can deprive students from using their initiative, encouraging surface/atomistic rather than deep/holistic learning. The obvious way of overcoming many of these problems is to give students motivation although in practical terms this can often be difficult to achieve. Many teachers, participants in the project have stressed various methods of teaching - learning mathematics. These may include compulsory reading of the recommended textbooks, detailed handouts, small group teaching and formative assessment.

In these conditions, the project we refer to aims to achieve a high European level in learning - teaching mathematics.

The reform of education envisaged the perspective of Romania's integration in Euro-Atlantic structures [4]. Efforts have been made for bringing learning back to school, the latter proving its efficiency by the abilities acquired by the young people, in accordance with the new social and economic reality after 1989. These abilities were proved not only formally, by a study diploma, but also in real life competitive situations on the Romanian and international labour market. 


\section{ASSESSMENT PROCEDURES}

Besides the process of reforming the curriculum, special attention has been paid to the reform of the assessment system, with a view to making the gradual introduction of a new assessment system possible. This system is oriented towards doing away with the entrance examinations to a higher educational level and creating the possibility for the mobility of young people both inside the country and throughout Europe. The effort of reforming the assessment system has focused on two main directions: on the one hand, the reform of final examinations and on the other hand the reform of assessment as a process, of current assessment, respectively, meant to record the progress of the students or the obstacles that they meet in coping with the formal exigencies of the curriculum.

The researchers of the Faculty of Applied Sciences (University Politehnica of Bucharest) created software tools that would let university students and teachers work together on structured, self-directed learning projects regarding both their training for entrance to the University and later the specialized training in the domains of Mathematics and Physics. The project offered the opportunity to use the Internet to collaborate with students outside regional boundaries. Using the Internet, a group of students can simultaneously learn the same subjects. A virtual research team could rapidly exchange findings and insights and collectively advance knowledge on a large frontier.

The promoters of this project believe that students gain new knowledge and skills most readily by working together with others on projects that they themselves define and manage, facilitated rather than controlled by teachers. This training project prepares them to be more self directed, teamwork oriented, and technologically adapted later in life. Because students need to be competent in self direction, social networking and collaboration in technologically mediated environments.

The project was initiated for the training of the entrance examination. The project is online. The students have access to the database of the project and they have the possibility to learn both by themselves and under the supervision of teaching staff, with feedback from the computer and/or from the professor. ILOs (Individual Learning Objects) contain bonus materials for more advanced students, are designed to elaborate papers on Applied mathematics for Students' Communications Sessions

Besides BOK (Body of Knowledge, which is common to all the faculties), the second part of the body of the project is Math Zone by Faculties.

This part contains chapters on mathematics with applications which are specific to technical curricula of each type of faculty (Electrical faculties, Mechanical faculties, Chemical faculties, Applied Sciences faculties)

It has a content similar to ILP except for a more focused approach to applications.

Quizes and Midterms are included into the system to cover theory and applications

Students' preparation in ILP and in Math Zone is done in the final examination which has the following features:

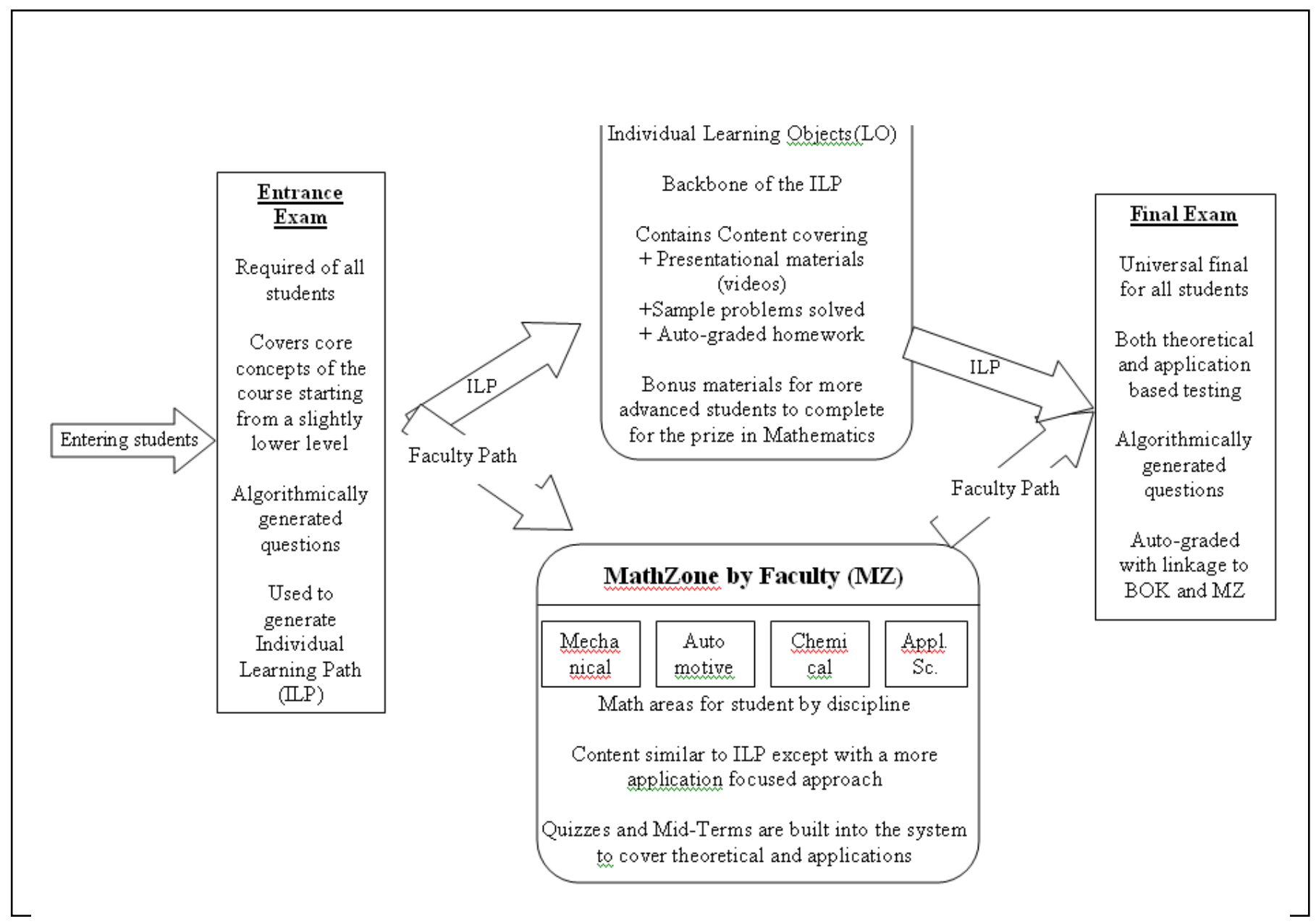


- $\quad$ universal final for all students

- $\quad$ both theoretical and application based testing

- algorithmically generated questions

- $\quad$ self-graded with linkage to BOK (Body of Knowledge) and MZ (Math Zone)

If the candidate fails, depending on the deficiencies indicated by the students' answers, a new ILP (Internal Learning Path) to redo the students' average is generated algorithmically.

The project will create next-generation support and advice services to enhance individual and collaborative building of competences and knowledge creation in educational and organizational settings.

The content of the assessment has been modified in relation to the intentions of diversifying and rendering flexible the assessment procedures. The semestrial periods of assessment are the periods when revisions are made, the knowledge is summed up and consolidated. These are activities that are necessary in any educational approach, current assessment continuing to be carried out under forms and in modalities that are much

diversified. It also includes new and interesting modalities such as project-like activities, folders of the latter, team activities, etc.

We must emphasize the importance of ARACIS, the Romanian Agency for Quality Assurance in Higher Education, through Government Emergency Ordinance no. 75/2005 Regarding Quality Assurance in Education, which became the Law nr. 87/2006 when adopted by Parliament, which has been responsible, according to the law, for assuring the quality and the accreditation procedures for higher education institutions. ARACIS activity includes commissions for external assessment of higher education institutions, in order to assure a temporary functioning authorization and of a later accreditation.

Each higher education institution is responsible for ensuring quality for all activities and at all levels, in agreement with the standards of reference, which are being updated. The quality management system within the higher education institution has as its objective the internal processes for assuring quality, including self-assessment at every level, in accordance with the standards of reference, including the requirements of the systems of external assessment of quality.

\section{AN EXPERIMENT ON STUDENTS' DEGREE OF KNOWLEDGE}

A survey was conducted to estimate the percentage $100 p$ of the students of the Faculty of Applied Sciences from UPB who answered positively the question "Is the course of mathematics X useful for the four courses of engineering?" using only two possible answers (YES or NO). The number of students to be interviewed was calculated so that, with a probability of 0.95 , the difference between the percentage corresponding to the selection and $100 p$ would be less than: 1)
$3 \%, 2) 5 \%$. Two subcases were considered: i) $100 p<25$; ii) $p$ is unknown.

Case 1. $3 \%$. The solution of this experiment was obtained by considering the number $n$ of the interviewed students, the probability $p$ of a positive response and the relative frequency of a positive response $\bar{x}$. Then $n$ is determined such that the following inequality holds:

$$
\mathbf{P}(|p-\bar{x}|<0.03) \geq 0.95 \text {. }
$$

Therefore the interval $(\bar{x}-0.03 ; \bar{x}+0.03)$ must be contained in a confidence interval for $\mathrm{p}$ of 0.05 level. Since $z_{0.975}=1.96$, formula (7.21) in [9] shows that such an interval is:

$$
\left(\bar{x}-1.96 \sqrt{\frac{p(1-p)}{n}}, \bar{x}-1.96 \sqrt{\frac{p(1-p)}{n}}\right) .
$$

Subcase i) $100 p<25$, i.e. $p<\frac{1}{4}$.

It follows that $\mathrm{n}$ satisfies the inequality $1.96 \sqrt{\frac{p(1-p)}{n}}<0.03$.

Since the function $f(p)=p(1-p)$ is increasing on the interval $\left[0, \frac{1}{2}\right]$, its maximum point in $\left[0, \frac{1}{4}\right]$ is $p=\frac{1}{4}$, hence $p(1-p) \leq 0.25 \cdot 0.75=0.1875$. Therefore $n$ verifies the inequality

$$
\begin{gathered}
1,96 \sqrt{\frac{0.1875}{n}}<0.03 \text { and one obtains } \\
n>\frac{1.96^{2} \cdot 0.1875}{0.0009}=800.33 \text { hence } n>800 .
\end{gathered}
$$

Subcase b) unknown. The maximum point of the function $f(p)=p(1-p)$ in $[0,1] \quad$ is $p=1 / 2$, hence $p(1-p) \leq 0.25$. One obtains $1.96 \sqrt{\frac{1}{4 n}}<0.03$, hence $n>1067$.

Case 2. 5\%. Similarly, one obtains in subcase i) $n>288$ and in subcase ii) $n>384$.

According to these solutions, a selection of 395 students was chosen and the survey was applied to two courses of mathematics, denoted here by X1 and X2. The result of the experiment was $28 \%$ positive answers for $\mathrm{X} 1$ and $63 \%$ for $\mathrm{X} 2$ and this result was taken into account in the change of the curriculum.

\section{CONCLUSIONS}

Thus, education must thus be viewed as fundamental to development, not just because it enhances human capital but because it increases social capital as well. 
The environment in which mathematicians operate is changing rapidly. If our community is to govern itself in a responsible manner, it is imperative that we understand and adapt to these changes. Our reluctance to examine difficult issues such as the determination of enrollment levels, immigration, changing faculty demographics, and the effectiveness of various types of training programs neither makes these issues disappear nor mitigates their effects [3]. The mathematical societies have the opportunity to take a strong leadership role here. Better information on the market for Ph.D.s and an assessment of the effectiveness of different types of training programs are not a cure-all prescription, but they do represent an important first step. The mathematical community needs to take a more active role in solving the current labor market problems and in preventing future ones. The future of the profession and the next generation of mathematicians depend upon it.

It is often said that pure mathematics is the study of mathematics for its own sake. Pure mathematics seeks clarity of understanding why things are the way they are. Graduates therefore may progress into research careers or apply the knowledge and skills of logic, mathematical modelling, experimental design, and the ability to manipulate, analyse and interpret large amounts of data into a broader range of career paths. Graduates find work in business, manufacturing, government, scientific and research fields.

\section{REFERENCES}

[1] Government of Romania, Ministry of Education and Research, Ordinance regarding the Assurance of Quality of Education no 75/12 July 2005.

[2] Government of Romania, Ministry of Education and Research, Romania's Contribution to the Debate on the Future 7th Research Framework Program of the European Union for 2007-2013.

[3] Joan E. van Aken, Management Research Based on the Paradigm of the Design Sciences: The Quest for Field-Tested and Grounded Technological Rules, Journal of Management Studies 41:2 March 2004.

[4] Ministry of Education and Research. Higher Education in Romania Progressing towards the Bologna Objectives, 2006.

[5] Ministry of Education and Research. The Romanian Education System. National Report, Bucharest, 2001.

[6] Niculescu P. Constantin, Report on the State of the Romanian Mathematical Education, Proceedings of the Sixth Congress of Romanian Mathematicians, Bucharest, 2007, Volume 2, Plenary Reports, pp. 21-47.

[7] Prepelita Raileanu Brandusa, Oana Pastae, The Role of Education in Mathematics to Maintain and Improve Economic Competitiveness on the Labor Market, International Conference on Educational Technologies (EDUTE'11), Iasi, Romania, July 1 - 3, 2011

[8] Solomon Marcus, Mathematics in the Romanian society and its scientific and cultural life, Report on the state of the Romanian mathematical education, Proceedings of the Sixth Congress of Romanian Mathematicians, Bucharest, 2007, Volume 2, Plenary Reports.

[9] Mircea Moroianu, Gheorghe Oprişan, Probabilităţi şi Statistică, Ed. Printech, Bucureşti, 2002.

\section{Creative Commons Attribution License 4.0 (Attribution 4.0 International, CC BY 4.0)}

This article is published under the terms of the Creative Commons Attribution License 4.0

https://creativecommons.org/licenses/by/4.0/deed.en US 